\title{
INSECTS AND ENTOMOLOGISTS:
}

\section{Their Relations to the Community at Large.}

\author{
By John B. Smith, Sc. D.
}

\section{$($ Abstract)*}

The importance of insects in their relation to the community at large has only become recognized during recent years, and the work of the entomologist is only now receiving the appreciation it merits. Entomologists in the sense used in the address include systematists, students of life histories and ecology and collectors; but not those studying only anatomy or histology or insects purely as hosts for disease-producing organisms.

Insects are injurious to man directly, as parasites, or as predatory forms attacking him, $e . g$., lice in the one case, biting flies in the other. Incidentally he may be harmed by urticating larvæ or such as shed barbed hair, like the brown-tail caterpillars.

Insects are further injurious as carriers of, and intermediate hosts for, disease-producing organisms: two totally different processes for, in the first case, the insect has no necessary relation to the disease, $e . g$., the house-fly to typhoid fever, while in the second the insect is a fellow sufferer, and the disease organism requires both man and insect to complete its life cycle, as in the case of the Plasmodia causing malarial diseases. The relation of mosquitoes to fevers, of flea to plague, and of Tsetse flies to the sleeping sickness was illustrated, and it was stated that if all dipterous insects, including fleas, could be at once eliminated, mankind would be at once freed from malarial, yellow, dengue, jungle, and several other kinds of tropical fevers, the bubonic plague, sleeping sickness, filariasis, several forms of eye diseases, certain ulcerating sores of tropical countries, and we would reduce to a minimum enteric fevers of all kinds, lessen the death rate from tuberculosis and pulmonary troubles, and probably modify or lessen leprosy and kindred diseases.

* This address was delivered before the Entomological Society of America and its friends on the evening of December 30th, 1909. It was a popular presentation of the subject, profusely illustrated by lantern slides, and not suitable as a whole for publication in a Scientific Journal. 
All domesticated animals and birds suffer from insect attack and parasites. Lice, bots, horse and stable flies, fleas and the like, and many animal diseases are carried by insects and their allies the ticks. Here also the Diptera contribute the bulk of the dangerous and troublesome species, and to our horses, cattle and sheep the elimination of all flies would be as great a boon as to man himself.

Insects also live with man as messmates, preying on his stored products or acting as scavengers in his dwelling, and all the main orders are represented in this heading. They are further injurious by feeding upon the crops grown by him, the annual losses figuring up to enormous sums - estimated at $\$$ I, $500,000,000$ for the United States alone. All parts of the plants above and below ground, outside and inside are infested, and all kinds of plants are attacked.

Many insects have been introduced from foreign countries and some have profoundly influenced our agricultural methods. The San José Scale has revolutionized fruit culture in the eastern United States and, incidentally, has made more positions for entomologists and stimulated more interest in entomological work, than all other species combined:-in which respects it is not an unmitigated pest.

There is, however, another side to this shield and there are also insects directly and indirectly beneficial. Bee products are of great value, and silk products are enormously so. Some insects are used in medicine, a very few for food, and a few also in the arts.

The chief value to man, of insects, is as pollenizers to plants, and many plants are entirely dependent upon them for their continued existence. Pollenizers are found among the Coleoptera, Lepidoptera, Diptera, and, pre-eminently, the Hymenoptera.

Portraits were shown, and brief notes were given of Say, Melsheimer, Haldeman, LeConte, Horn, Abbot, Morris, Grote, W. H. and Henry Edwards, Hulst, Strecker, Clemens, Hagen, Osten-Sacken, Loew, Ashmead, Packard, Scudder, Harris, Glover, Fitch, Walsh, LeBaron, Riley, Lintner and Fletcher. A few collectors and founders of early societies were also referred to, Akhurst and Schaupp of Brooklyn, the latter one of the founders of the Brooklyn Entomological Society, and Feldman, of Philadelphia, ancestor of three generations of Coleopterists - the Wenzels - after whom the Feldman Social was named. Pictures of field 
meetings of the New York, Brooklyn, Newark and Philadelphia Societies in New Jersey were also shown and the address thus summarized.

" *** insects are a factor of very great importance in the community, first, because of their injuries, direct and indirect; second, because of their benefits, also direct and indirect, and millions of dollars annually are involved on both sides of the ledger."

"The entomologist who studies these insects, determines which are harmful and which are beneficial, who works out their life histories and habits and who determines methods of controlling those that are harmful and improving those that are beneficial, is a worker of high importance to the community and deserving of every possible aid and assistance.' 


\section{$2 \mathrm{BHL}$ Biodiversity Heritage Library}

Smith, J B . 1910. "Insects and Entomologists: Their Relations to the

Community at Large." Annals of the Entomological Society of America 3, 12-14. https://doi.org/10.1093/aesa/3.1.12.

View This Item Online: $\underline{\text { https://www.biodiversitylibrary.org/item/38713 }}$

DOI: https://doi.org/10.1093/aesa/3.1.12

Permalink: https://www.biodiversitylibrary.org/partpdf/193738

\section{Holding Institution}

Smithsonian Libraries

\section{Sponsored by}

Smithsonian

\section{Copyright \& Reuse}

Copyright Status: NOT_IN_COPYRIGHT

This document was created from content at the Biodiversity Heritage Library, the world's largest open access digital library for biodiversity literature and archives. Visit BHL at https://www.biodiversitylibrary.org. 